1935

\title{
Intracranial complications of otitis media
}

George L. Tracewell

University of Nebraska Medical Center

This manuscript is historical in nature and may not reflect current medical research and practice. Search PubMed for current research.

Follow this and additional works at: https://digitalcommons.unmc.edu/mdtheses

Part of the Medical Education Commons

\section{Recommended Citation}

Tracewell, George L., "Intracranial complications of otitis media" (1935). MD Theses. 641.

https://digitalcommons.unmc.edu/mdtheses/641

This Thesis is brought to you for free and open access by the Special Collections at DigitalCommons@UNMC. It has been accepted for inclusion in MD Theses by an authorized administrator of DigitalCommons@UNMC. For more information, please contact digitalcommons@unmc.edu. 
THE IFTRACRANIAI

COMPLICATIONS OF OTITIS MEDIA

George Iogan Tracewell

Senior Thesis

Univeraity of Nebraska

College of Medioine 
Apri1 1935 
COWHPIIS

Page

TEMPERATURE CHART.........................4

HISTORICAI INTRODUCTION.................

THE INTRACRANIAI COMPIICATIONS OF OTITIS MEHIA.....12

Pachymeningitis Externa \& Extradural Abscess..17

Sinus Thrombosis....................18

\begin{abstract}
Bratn Abscess........................25

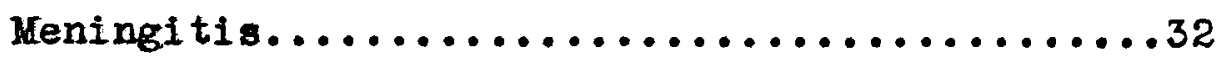

CONCIUSIONS.............................42

BIBII OGRAPHY. . . . . . . . . . . . . . . . . . . . . . 49
\end{abstract}

(1)
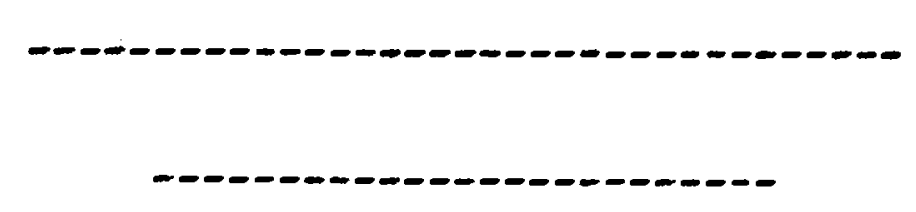

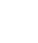




\section{Temperature Chart}

Characteristic temperature \& pulse-rate in intracranial complicatjons.

\begin{tabular}{|l|c|c|c|c|c|}
\hline Date & Brain & Meningitis & Sinus & \\
\hline Dayof & Aliness & Abscess & & & Thrombosis \\
\hline
\end{tabular}

\section{Hour}

107

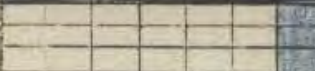

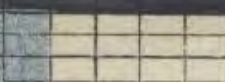

그

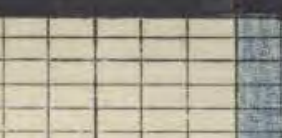

-

(

10

| $104^{\circ}$

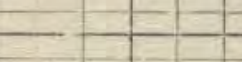

$100^{\circ}$

$99^{\circ}$

Normal
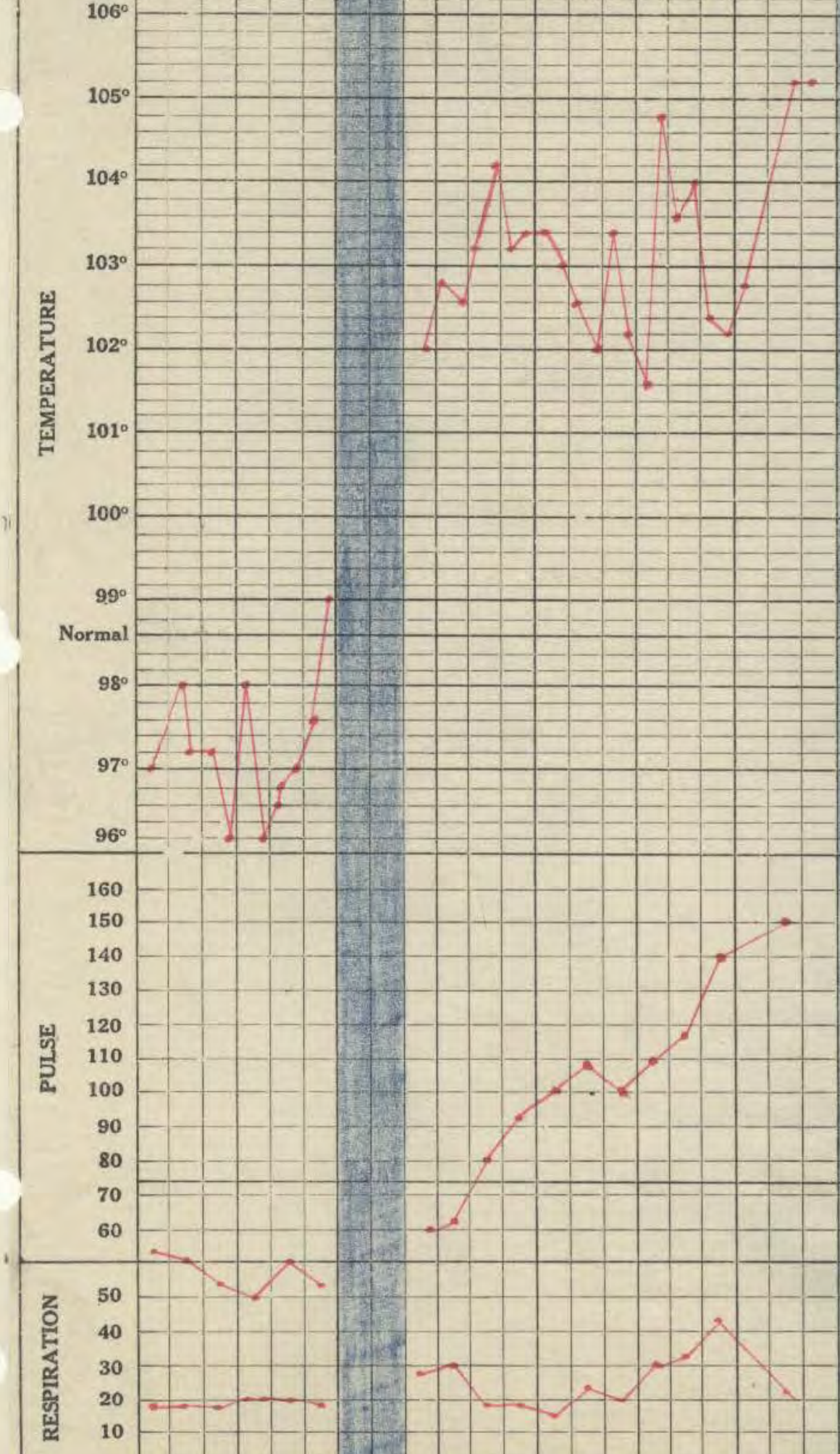
EISTORICAI INTRODUCTION

The ancients were cognizant of the danger of certain disases of the ear. Hippocrates (460--350 B.C.) wrote: (1) "Acute pain in the ear with continued strong ferer is to be dreaded, for there is danger that the man may become delerious and die. Since, then, this is a hazardous spot, one ought to pay particular attention to all these symptoms from the commencement. Younger persons die of this disease on the seventh day or still earlier, but old persons much later; for the fevers and delerium less frequently supervene upon them, and on that account the ears previously come to a suppuration; but at these periods of Iffe relapses of the disease coming on generally prove fatal. Younger persons die before the ear suppurates; only if white matter run from the ear, there may be hopes that a younger person will recover, provided any other favorable symptom be continued."

(2) Over one hundred years before Hippocrates was born the eustachian tube was discussed by Alcmaeon, 570 B.C. There is some evidence that Aristotie knew of this about the year 322 B.C., although no clear and accurate description was given until Bartholomeus Eustachius described it in 1604. Since that time to the present day it has born his name. 
The cochlea was first discussed by a Greek, Eupedcles, 400 B.C. while the acoustic nerve was described by Erastratus, an Egyptian, during the early dissection carried on in the time of the Ptolemys. The helix, lob, tragus and anti-tragus were first described by Ephesus about 100 B.C., and in tribute to him let it be said that this is the generally accepted nomenclature of today.

(3) The 5 th and 8 th nerves were described as one by Marinus, the preceptor of Galen. From Galen's time down to the 15 th century there was little discovered about the ear. Galen corrected the idea that the 5 th and 8 th nerves were the same, and showed that the 8 th entered the internal auditory canal. He gave an inkling as to the general plan of the internal ear by calling it a labrynth, believing that the external auditory canal ended in the dura mater.

There is no record of the ossicles of the ear until the 15th century. An Italian anatomist, Alexander Achilline generally has the credit of discovering these, and it is probable that he and Jacob Berengario first described them, although they did not discover them. This description did not include the stapes.

Berengario was the first to describe the membrani 
tympani, although he thought the origin of it was in the acoustic nerve or the meninges.

Andreas Vesalius, 1514-1564, who was the most exact anatomist of his day, described the long process of the malleus, the eustachian tube, the restibule, and the semicircular canals. Ingrassia, Colombo, and Eustachius all claimed the honor of the discovery of the stapes. The weight of evidence was in favor of Ingrasia.

It remained for Gabriel Follopius, 1523-1562, to show that the mastoid cells communicated with the tympanic carity. He gave his name to the oanal through which the facial nerve runs in the tympanic cavity. Julius dasserius, 1593-1609, was the first to describe the two and a half turns of the cochlea. The function and physiological action of the ceruminous glands were first described by stenson in 1665 .

In the 18th century, Valsava far exceeded his predecessors in the amount and exactness of his knowledge. He deroted more than 16 years of his life to the study of the ear and for the purpose of his study dissected more than one thousand heads. He discovered the muscle that opens the eustachian tube and lifts the soft palate. He also showed that the fenestra ovalis was covered by a membrane. 
In 1761, two important contributions were made. Dominic Cotuguo discovered the fluid in the babrynth, and Antonia Scarpa issued a work on the structure of the ear which was the last word in the anatomy of this organ. Alexander Monro, 1797, was the last of this series of wonderful anatomists. He traced the auditory nerve within the cochlea, vestibule and semi-circular canals.

(4) The first successful mastoid operation was performed in 1736 by Jean Iouis Petit, a French surgeon at the University of Paris. His observations on the subject show that he clearly appreciated the reasons why operation was necessary.

(5) A fellow Frenchman; Guyot, was the first to catheterize the eustachian tubes, 1724, while an excellent description of the nerve endings of the labrynth was written by Max Schultze in 1858. Helmholtz wrote concerning the mechanics of the ossicles and membrana tympani, 1860, and (ㅁ) in 1870 Goltz discussed the physiological significance of the canals.

(6) Notwithstanding the fact that England lays claim to the pioneers in aural surgery of the 19 th century, pointing to the fine work of Sir Astley Cooper (1801) and Sir William Wilde (1843-53); much of the early and modern surgery of the ear and mastoid has been developed by the Germans. In 1873 Hermann Schwartze and Adloph Eysell des- 
cribed the method of opening the mastoid by chiseling. This operation was further improved by manuel 2 aufal (1884) and Ernst Kuster (1889), while Ludwig Stacke introduced excision of the ossicles in 1890 and greatly improved the surgery of the middle ear.

Aural vertigo was first described by Prosper Meniere in 1861. while the relations between nystagmus and vestibular or cerebellar disease had been noted by Purkingje and Flourens, and have been developed in the 20th century by Robert Barany.

(7) As for the American pioneers in otology, the writer desires to mention only a few: Edward Delafield and John Kearney Rodgers established the New York Eye Infirmay in 1820. This infirmary, the forerunner of the renowned New York Eye and Ear Infirmary had a modest beginning in two hired rooms on the second floor of a house at 45 Chatham Square, New York. In 1823, facilities for the treatment of diseases of the ear were provided and in 1864 the title was officially changed.

In 1821, Dr. George McClellen established the Institution for the Diseases of the Eye and Ear at Philadelphia. This seems to have been largely a one-man affair and after 1824 there is no record of its activities. Dr. William Price, 1788-1860, a surgeon of the Penn- 
sylrania Hospital brought out in 1821 the "Anatomy of the Human Ear", the American edition of Dr. John Cunningham Saunders Bnglish work, giving us the first book on the ear published in the United States.

Dr. Nathan R. Smith, 1797-1887, brought out the second book on the ear in this country (1829), a translation from the French of J. A. Saissy's "Diseases of the Internal Tar." To this he added a supplement of his own on "Diseases of the Bxternal Ear."

Dr. Joshua I. Cohen, 1801-1870, of Baltimore was another of the pioneers in American Otology. He was the earliest, if not the first, to confine his practise to diseases of the ear. His only written contribution to otology was Postmortem Appearances in Case of Deafness, published in 1842 .

A large volume might be written on subsequent workers in this field, and it is with regret that the writer leaves unmentioned many of our countrymen who have made important contributions to otology. Iittle has been said of work in our present century, either here or abroad, as a comprehensive review of recent research and its results is beyond the confines of this brief sketch. It is interesting to note, however, that our present state of knowledge has not been acquired over a brief period, but is rather the result of many centuries of intense study, painstaking research, and carefully recorded observation. 


\section{THE INMRACRANIAI}

\section{COMPIICATIOHS OF OTITIS MEDIA}

In purulent infections of the middie ear there is an involvement of the mastold process in a very large percentage of cases. When pus has collected in the middle ear in sufficient quantities to cause only slight bulging, it may be assumed that the pus has already invaded the antrum and the adjacent mastoid cells which communicate with it. The middle ear does not have to be full of pus and under tension to cause extension to the mastoid. The antrum is not closed off from the middle ear by any barrier that requires force or pressure to break it down. It is directly connected with the antrum of the midale ear through the aditus; a channel that is always open.

If patients with a purulent otitis media were always in an upright position, it might be true that pus would not reach the aditus until the middle ear was completely filled, as the opening into the antrum is at a high level. However, patients with otitis media do not keep their heads erect all of the time, and consequently infective material in the tympanic carity can easily flow into the antrum. This may occur, despite the fact that only a small amount of pus is present.

When infected matter reaches the antrum and adjacent mastoid cells, whether or not an active mastoiditis is set 
up depends on a number of factors. Briefly, they are the virulence of the infective organism, the resistance of the patient, and the drainage from the middle ear, either through the eustachian tube or the incised or spontaneously ruptured drum. The great majority of such infections of the antrum and adjacent cells recover without an active infection of the mastoid, but others go on to involvement of the cells, pus formation, and cell wall destruction. Active purulent mastoiditis is not of itself a serious menace to iffe. It is the complications that accompany or follow mastoiditis and otitis media, that result in impairment of the functions of the ear and seriously endanger ilfe.

(8) In a study of intracranial complications of otitis media observed at Cook County Hospital during eleven years, It was found that $10 \%$ of the total number of cases of suppurative otitis media had some form of intracranial involvement.

(9) In a series of 800 cases of mastoiditis operated upon in the Leed's Infirmary during a year and a half, and reported by Nunby and Jewit in the British Medical Journal for JuIy, 1926, the incidence of the complications was 147, or 18.1\%. Durigg the year of 1926, a series of 123 mastold operations were reported from six of the hospitals in seattle. Twelve complications were reported. In the Leed's serles brain abcesses occurred in 
8.9\% of all cases; lateral sinus thrombosis in $5 \%$ and and purulent menigitis in 2.5\%. In the seattle Hospitals 10\% were lateral sinus thrombosis, while the other two complications were less than $1 \%$ each.

In considering the spread of infection from the tympanic cavity, there are many factors to be considered. According to Beck, as quoted by M. L. Breitstein (10), these factorsimay be grouped as follows:

1. Loci Minores resistance which occur normally.

2. Unusual clefts and fissures which occur anatomically or which have not closed down.

3. A breaking down process of the surrounding bone.

4. The lymph drainage of the middle ear.

Under the first heading may be considered the fibrous tissue connection between the bone cartilaginous cana, the rascular communication between the auditory cana and the mastoid cells, the variation in thickness of different parts of the mastoid cortex, and the degree of pneumatization of the mastold process.

This development of the mastoid cells has much to do with the complications following their infection. It has been found that there is a great variability in the amount of pneumatization of the mastoid in different people. 
While ordinarily the mastoid process is underdeveloped and has not become pneumatized in infants, it has not infrequently been found that a child under a year old has extensive derelopment of the cells. On the other hand, in some adulta only a part of the process is ever invaded by cells. In such cases there might be no cells close enough to the sigmoid sinus to cause its infection by directiextension. In other cases with an extensively pneumatized mastoid, the cells may be in close proximity to the sigmold sinus, the dural covering of the brain, the facial canal, the internal ear structures, and other cranial nerres, so that an infection would be more likely to cause complications in these structures.

In considering unusual clefts and fissures, it may be mentioned that dehiscences occasionally occur in the wall between the auditory canal and the antrum. More rarely there are dehiscences in the floor of the antrum, the tegmen tympani, and in the posterior wall of the carotid canal. These defects are important in the transmission of infection to the structures adjacent to them. The factor of the breaking down process of the surrounding bone is to be considered chiefly in a study of the type of infecting organisms. Those of greater virulency cause a quicker and more complete breaking down 
of the bony tissue and therefore are more apt to cause complications. The most virulent type of organism has been found to be the streptococcus mucosus capsulatus, while next in order comes the steptococcus hemolyticus.

In considering the lymph drainage of the middle ear, there are two poosible way for Iymph drainage to occur in otitis media:

1. Through the drum to the lymphatics of the exterasl auditory canal and pinna.

2. Through the lymph ressels of the eustachian tubes to the glands in the lateral retro-pharyngeal walls.

(II) No Iymphatic communication between the ear and the meninges has erer been found.

While Beck did not stress the importance of the blood vessels, they are an important route for the transmission of infection. (12) Pietrantoni has demonstrated that the venous circulation of the tympanic cavity is in direct relation to the inferior petrosal sinus, independently of the internal auditory reins; also that there exist direct renous relatinns between the tymanic cavity and the apex of the petrous bone, as well as between the latter and the gasserian ganglion and the abducens nerve.

(24) Crane states that the vein of Trolard, which arises on the parietal convolution and empties into the cavernous sinus, recelves blood from the diploic veing, 
which communicate with the reing of the tympanum.

Compications following mastoid infections depend to some extent on the type of mastoiditis. (14) Kopetsky has pointed out that the infection of the mastoid may occur as the coalescent or the hemorrhagic type. The former occurs with the formation of pus within the cellular structure and the breaking down of the cell walls to form an abcess carity within the mastoid cortex. This type of mastoiditis is much more apt to give rise to perisinus abcess. Iateral sinus thrombosis and extra-dural abcess than are cases of hemorrhagic mastolditis.

This latter type consists of an involvement of the mucous membrane lining the mastoid cells, which becomes thickened and swollen with intense congestion of the ressels, and the formation of small thrombi within the venules. There is nok breaking down of the cell walls, and the cell spaces contain no pus, but are usually filled with blood tinged serum or blood. The formation of the thrombi is natures attempt to localize the infection of the mastoid cells. At first the thrombi are of the honinfective type, but they may easily become infected because of the close contact with the causitive microorganism present within the mastoid cells, and may then give rise to systemic infection or break down to form nus. This type of mastolditis gires rise to systemic 
infection earlier than the coalescent type and without lateral sinus thrombosis. but is less apt to result in extradural abocesses.

\section{Pachymeningitis}

\section{Externa extradural Abscess}

(15) Pachymeningitis externa and extradural abscess or perisinuous abscess are the most frequent otogenic indocranial complications. They occur in the middle and posterior cranial fossa. especially in the region of the tegmen tymani and of the sigmoid sinus, but also further medially, on the posterior pyramidal surface and even at the pyramidal apex. The extradural suppurations often take their course without special symptoms aside from thos of the original ear suppuration. Fever is usually absent. Eventually, an increase of the secretion from the middle ear during intervals, the appearance of a swelling above the concha, indicating perforation of the quamous portion of the temporal bone, or behind the mastoid process, indicating suppuration from the emissarium mastoideum, or else, the evolvement of definite local cerebral svmptoms or of symptoms of general cerebral pressure, may point to an extradural abecess. However, an extradural abscess is usually not diagnosed before the operation, and not then anzess the 
operation is radical. This does not mean that the cranfal fossae should be opened in every case, but certainly all suspichious parts of the mastoid process should be radically removed. When this is done, the outcome is is favorable, if the contents of the dural sac have not been previously infected.

\section{Sinus Thrombosis}

(16) Sinus thrombosis usually arises from a diseased mastoid process, but may also arise from the tympanum, from a labyrinthogenic empyema of the saccus endolymphaticus, from deep perilabyrintaine cells, and finally, from an otogenic meningitis or a cerebral abscess.

The sigmoid section of the sinus transversus is the most endangered. Transmission to the bulb of the jugular rein is rare. Transmission to one of the petrosal sinuses may occur, and while it is exceptional, transmission from the anterior end of the tympanum to the cavernous sinus may occur.

In the great majority of cases, sinus thrombosis in acute and chronic suppurations of the middle ear, forms by penetration of pus from a suppurative or destructive focus in bone. It travels by direct extension or by normal or pathological vascular com- 
munications between the mucous membrane of the middle ear and the periosteum of the dura. In the latter case the course is of the fulminating,type. The inflammatory processes may remain confined to the wall of the sinus without visible formation of thrombi although bacteria and toxins are being sent into the blood stream. In the majority of cases however, thrombosis develops, primarily parietal, sooner or later, obturative.

(17) In some cases, the thrombosis is a protective process, barring the way to infection. All who are familiar with the pathogenesis of sinus thrombosis will realize that in persons with chronic mastoiditis, the wall of the simus may be gradually compressed, once the inner table is eroded. In this way the channel is narrowed and the blood stream is slowed. When the intima is injured a sterile thrombus forms and this is soon organized so as to obliterate the rein. In the majority of cases, however, the thrombus does not fulfill this protective function, but suppurates and forms the septic focus for otogenio ganal infection.

(15) Sinus thromboses grow in both directions of of the blood stream. They may be confined to a certain section of a sinus, but may also be propagated in a central or peripheral direction. In the first instance 
they may extend as far as the jugular vein, and in the second, as far as past the torcular Herophili, into the transterse sinus of the other side, the Iongitudinal ginus and the petrosal and cavernous sinuses. Clinically otogenic sinus thrombosis and general infection either take a pyemic or a septic course. The former is characterized by a jagged pyemic temperature curve, with or without chills, and by the appearance of metastases in the musculature, the subcutaneous cellular tissue, the joints, the internal organs and especially, the lungs. The septic course is characterized by a high continued fever, a small filiform pulse, rareness of chills, cerebral symptoms and delirium. Detachment of larger emboll and formation of abscess are rare. Hence there are none of the symptoms caused by larger infarctions, while septic endocarditis, nephritis, hepatitis and enteritis not infrequently develop. A splenic tumor is present in a majority of cases. However, the course is seldom purely pyemic or septic, but usually septicopyemic.

A raluable diagnostic aid is the sign of general infection, which as a rule points to sinus thrombosis, if otitis media is present. This is expressed by evidences of metastases, such as hemorrhagic nephritis, acute rheumatism, etc. 
Inasmuch, however, as metastases occur in only about $40 \%$ of cases, other signs have great clinical importance. The fever, especially the persistance of pyemic temperatures, and, in their absence, the following significant peculiarities, should be studied: Acute suppurations of the middle ear take their course, especially in adults, with or without slight increases of temperature, except in the initial stages. For the first few days to a week, higher temperatures may prevall without forming an indication for early operation. After that, an increase in temperature, in the course of an otitis media, which had either been non-associated with fever or was already in the stage of defervescence, points to an endocranial complication--sinus thrombosis. The same is true, on the whole, of fever in chronic suppurations of mucous membrane or of the bone.

(18) For differential diagnosis, other complications associated with ferer arising from the propagation of the infectious-inflammatory process beyond the mucous membrane of the middle ear must be born in mind. Suppurative inflammations of the labyrinth cause high temperatures if the meninges are involved. They are differentiated by disturbances of equilibrium, labyrinthine nystagmus, vertigo, vomiting, deafness, and non-sensitiveness to caloric stimulation. Pachymeningitis, extradural abscess and cerebral 
abscess are differentiated by a less high fever. Leptomeningitis, pachymeningttis interna and subdural abscess and a latent cerebral abscess becoming manifest, are associated with high fever, but usually also with meningitic and focal symptoms. If the symtoms are vague, lumbar puncture is necessary.

(19) Diseases and complications other than otic, but associated with fever and appearing in the course of an otic suppuration must be considered: Erysipelas, influenza, tonsilitis and other acute inflammatory diseases of the pharyngeal and naso-pharyngeal space; the so-called secondary fever in measles, central pneumonia with an atypical course, typhoid fever and malaria. High fever may set in a few days before erysipelas becomes manifest, or the first manifestation may be hidden in the hair, while a swollen area appears behind the ear. In this case, extremely severe sensitivity to pressure of the mastoid process and its skin speaks for an oncoming erysipelas; the demonstration of bacteria in the blood, usually against it. Typhoid may be differentiated by the demonstration of the bacillus in the blood, the postive result of a Widal test, and the presence of leukopenia. For malaria, the demonstration of the plasmodium is essential for postive diagnosis. Occasionally, tuberculosis, especially in childhood, acute 
rheumatism of the joints, a puerperal or other focus simulates sinus thrombosis in the presence of middle ear suppuration. Besides the evaluation of the fever, the demonstration of the specific organisms in the circulating blood is of paramount diagnostic value.

(16) Local symptoms pointing to the presence of endocranial stasis and inflammation are: Headaches, delirium, deep profound sleep, optic neuritis and choked disk, qualitative and quantitative changes of the cerebrospinal fluid, swelling of the soft parts in the region of emissaria, such as in the posterior circumference of the mastoid process, the nape of the neck and the temporal region, and, especially, the appearance of a swelling in the region of the jugular vein and injury to to the nerves running through the foramen lacerum medium. If sinus thrombosis is already diagnosed, the abore symptoms announce the advance of the thrombophlebitic process.

These symptoms refer to the transverse sinus, which is the fost frequently affected. Thrombosis of the petrosal sinuses does not cause characteristic symptoms. Thrombosis of the cavernous sinuses is expressed by edema of the eyelids and bulbar conjunctiva, pfotfusion of the eyeball, optic neuritis, paralysis 
of the muscles of the eye and disturbances of the trigeminus. All these symptoms together, represent the classical syndrome of thrombosis of the sinus cavernosus. Each by itself is not dependable proof. By surgical exploration of the sinuses and their contents, the diagnosis of otogenic sinus thrombosis may be definitely confirmed, and the exact site of the trouble located. (20) The treatment is exclusively surgical. Nonoperated cases usually prove fatal. When operation is is performed early enough, and the entire diseased region is eliminated; that 1s, the primary focus in the middle ear removed, the diseased sinus exposed until healthy tissue is reached, the wall of the sinus opened and its thrombotic contents evacuated until blood flows from everywhere from the central to the peripheral end, the cases operated upon are usually saved. If the thrombosis, transgressing the torcular Herophili, extends to the transverse sinus of the other side, the latter must be opened in the same manner. A clot extending as far as the jugular bulb may also be handled in like fashion. The jugular vein may be Ifgated to prevent transportation of infectious material. Dr. Potts of Omaha seems to favor the latter procedure. He also suggests packing the infected sinus with iodiform gauze, as a method of locallizing the infection. Medical treatment of sinus thrombosis is of little 
arail, but stimulation of the general resistance is of paramount importance. Fifty years ago, before the era of operative treatment for sinus thrombosis, $90 \%$ of the cases ended fatally. In his article of January $30 \mathrm{th}$. 1932, in the Journal of the A. M. A., Dr. Potts reports a series of $6 I$ cases, operated by Doctors Gifford, Patton, Callfas, Cassidy and himself, in which $86 \%$ of cures and $14 \%$ of fatalities occurred.

\section{Brain Abscess}

(21) Otogenic cerebral abscess occurs more frequently in the course of chronic suppurations of the middle ear than tin thecodurse of, or following, acute ones, This is especially true when the chronic process is associated with cholesteatoma.

(22) In rare cases, the mucous membrane alone is affected. In the majority of cases, however, an extensive disease of the bone is present. The otitic cerebral abscess is practically always located in the cerebral portion adjacent to the diseased temporal bone. This is of marked etiological and diagnostic importance. It is usualiy solitary, although rarely multiple. Abscesses of the temporal lobe are more frequent than abscesses of the cerebellum. Some cerebral abscesses are encapsulated. In about 50\% of cases, strept- 
ococci are found in the pus. After chronic suppurations of the middle ear, anaerobia are demonstrable in $20 \%$ of the abscesses.

The propagation from the middle ear to the endocranium is the same as in other otogentc intracranial compbications. Whether the infection is transmitted to the midde or the posterior cranial fossa, determines if a tempral lobe or a cerebellar abscess forms. For the latter, a labyrinthine suppuration serves as an intermediary, especially in chronic otitis. Cerebral abscesses may also form in sinus thrombosis and in meningitis, either by metastasis or by thrombosis of the cerebral veins.

There are three stages in the clinical course of cerebral abscess; initial, secondary and terminal. The initial stage is associated with ferer, headaches and nausea. Howerer, since these symptoms are transient and also accompany chronic suppuration of the middle ear, they are seldom correctly interpreted.

In the secondary stage, there are distinct symptoms of cerebral abscess, usually discovered by exact neurological examination. In the terminal stage, the symptoms of perforation of pus into the ventricles or into the subarachnold spaces veil the picture. A sure diag- 
nosis is therefore only possible in the secondary stage. The symptoms fall into three categories: general symptoms, general cerebral symptoms, and local cerebral symptoms.

The disturbances of the general condition are fatigue, a sallow complexion, lack of appetite, constipation, and fever. Because the latter is usually present in the inttial and terminial stages, its evaluation is difficult. In the initial stage, it may be attributed to the otitic suppuration which is present, and in the latter to meningitis. High temperatures and severe chills are rare in cerebral abscess, although they may occur. (23) General cerebral symptoms which may be noted are constant headaches of raried degrees and types. The localization does not permit any conclusions with regard to the site of the cerebral abscess. Sensitivity to percussion, especially in the temporal region is more significant. Later, nausea and romiting appear, more freguently in cerebellar than in cerebral abscesses. Vertigo is usually present, but is not of a constant and uniform type. Vertigo also appears in diseases of the labyrinth. The sensorium and the psyche are very often deranged. Mental laziness, sleepiness and moodiness, hesitating and grouch answers, relieved by talkativeness, may appear. However, these phenomena are 
best judged by watching their appearance. A slackening pulse, and the appearance of optic neuritis or of choked disk are significant symptoms. Nevertheless, it should be born in mind that they appear in other intracranial complications, and that extensive cerebral abscesses may occur without them.

Iocal symptoms of a cerebral or focal nature may be due to direct lesions of cerebral nerves within the cranial capsule, or to indirect and distant effects. Deafness of the non-diseased ear is a focal symptom, seldom observed but very significant. This is due to the fact that the diseased temporal bone contains the auditory center for the contralateral ear. Testing of the non-diseased ear should therefore nerex be neglected. Right handed people with abscesses in the central lobe very often show sensory disturbances of speech, amnesic and optic aphasia, sometimes associated with agraphia, alexia and anarithmia. Amesic aphasia is the most frequent. Daily tests should be made so that its appearance will not be overlooked. The predominant local symptoms of cerebellar symptoms are cerebellar ataxia and rertigo. They may be absent if the abscess is small, and they may be present in cerebral abscesses and digeases of the labyrinth. The aymptoms due to distant effects may be of a 
mechanical nature, due to pressure of the abscess on the brain and increased tension of the cerebrospinal fluid, or it may be due to encephelitis and processes of softening in the neighborhood. They are more significant in cerebral otogenic abscesses, inasmuch as the distant effect starts from a definite point, and due to anatomical conditions, is confined to certain limits and directions.

A frequent distant effect of abscess of the temporal lobe is the appearance of phenomena from part of the internal capsule. These are pareses of the contralateral extremities, contralateral spasms, convulsions and tonic cramps, pareses and occasionally spasms of the contralateral facial nerve, contralateral hemianesthesia and homonymous bilateral hemianopsia.

Cerebellar abscesses may, by distant effect, cause injury of the pons and the medulla oblongata. This may lead to homolateral and contralateral hemiplegias, conjugate paralysis of the eye muscle towards the diseased side, andiditurbanes of respiration with possible death due to respiratory paralvsis. The oculomotor and abducens are the nerves of the cranial base most frequently involved in the distant effect. Sometimes homolateral paralysis of the hypoglossus and neuralgias of the trigeminus appear. (24) Abscesses of the left temporal lobe, in righthanded individuals are most easily diagnosed from the 
presence of the sensory disturbances of speech. However, the latter may elso be caused by encephalitis due to an extradural abscess and by circumscribed meningitic changes. Vertigo, nystagmus, cerebellar ataxia and adiadokokinesis point to an abscess of the cerebellum. Since cerebellar abscesses are very frequently caused by suppurations of the labyrinth, the presence of a labyrinthitis is significant, although it may also veil the picture. Considering the many common symptoms, cerebellar abscess and labyrinthitis are very difficult to differentiate. An accurate vestibular test and a test of hearing are indispensable. A rapid increase of deafness, and nonsensitivity of the vestibular apparatus point to labyrinthitis.

The evaluation of nystagmus is, in many cases, very important. Labyrinthogenic nystagmus is usualiy in the direction of the healthy ear, and its intensity decreases in the course of the disease. Cerebellar nystagmus, on the contrary, is directed towards the diseased side and increases in the courge of the disease.

If in the presence of one normal ear, the labyrinth of the diseased side is non-responsive to irritation and nystagmus towards the healthy side is present; this points to cerebellar abscess. If a nystagmus primarily directed towards the healthy side suddenly turns to the diseased side, this also points to cerebellar abscess. 
For the differentiation of cerebral abscess and meningitis, the result of the analysis of the cerebrospinal fluid is decisive.

For differential diagnosis, tubercles of the brain, tuberculous meningitis, especially in children, and tumors of the brain must be born in mind. Multiplicity of symptoms points to tuberculosis. An accurate roentgenographic and ophthalmocopical examination, combined with the analysis of the cerebrospinal fluid, helps to clarify the picture.

Tumors of the brain are characterized by the absence of symptoms pointing to infection, and espeoialiy by the negatire otic examination. Cerebellopontine tumors show a slow evolution, except in the case of cysts, and lead to early total paralysis of the acoustic and facial nerves. The cerebrospinal fluid obtained by lumbar puncture is normal.

Hysterical persons with suppurations of the middle ear sometimes show a syndrome reminiscent of cerebellar abscess.

The most important diagnostic procedure, however, is operation upon the ear, permitting exploration by exposure of the usual points of propagation, and exploratory exrebral puncture. 
(15) The therapy of otogenic cerebral abscess is surgical. Its aim is to remore the primary focus in the middle ear, eliminate the paths of propagation, and open and evacuate the abscess. The otosurgical techniques have advantages over the surgical techniques, inasmuch as they seek and empty the abscess in the same order in which it formed. This procedure is easier and should involve less danger of infection than the inverse order.

\section{Meningitis}

(21) Otogenic meningitis may be subdivided into subdural suppuration, serous circumscribed and diffuse suppurative meningitis. The propagation of suppurations from the temporal bone to the endocranium occurs in the manner already described. The intermediary role of extra dural abscesses and labyrinthine suppuration is important. If the infectious inflammatory process has reached an penetrated the dura, the suppuration may, transiently at least, remain localized on the internal surface of the dura or in the subdural apace. Several more or less extensive subdural abscesses may arise in this case. Furthermore, the suppuration may reach the soft meninges in a circumscribed spot, causing a circumscribed meningitis. More commonly, it spreads rapidly, leading to a diffuse meningitis. 
(25) A knowledge of anatomical and pathological changes is of paramount inportance. The exudate may show all xariations, from a clear limpid fluid to thick pus. The serous aspect of the markedly increased cerebrospinal fluid may be the expression of a bland infection in which the exudate conserves its serous character until recovery. It may also be present in the severest forms of leptomeningitis, in which death is due to toxic poisoning of vital centers. In these forms, a macroscopical reaction of the soft meninges may be missing. In the former, this may be because the irritation is too slight to cause inflammation, and in the latter, because the time for reaction is too short.

It is worth mentioning, however, that even in the presence of a purulent cerebrospinal fluid, the macroscopical changes in the meninges may be slight, They are never missing, however, if visible pus is present in the meshwork of the arachnoid space. It is important for the interpretation of clinical pictures, that, in suppurative, and even in serous, meningitis, local suppurative infiltration of the cerebral substance (meningo-encephalitis) may form. This, in the form of a cortical abscess, may reach a considerable ex- 
tension.

For the curability and prognosis of meningitis, the point of departure and its local propagation play an important role. Otogenic meningitis takes its origin where the process of suppuration, coming from the temporal bone, reaches the endocrainium. It is, however, not necessary that the most marked changes be located there. Sometimes only slight ones are found here, and very marked ones, at the base or at the convexity.

The focus-like propagation in the form of isolated patches is also important. From a clinical-operative viewpoint, it is important that, in labyrinthogenic meningitis, the changes in the form of abscesses in the porus acousticus may remain circumscribed for some time, and that the first arachnoid exudates appear in the cisterna pontis.

The all-important question of whether or not there are circumscribed and spontaneously curable suppurations of the arachnoid, must be answered affirmatively.

(26) As for symptoms, they are the same, on the wholes as those of traumatic, epidemic, or tuberculous, meningitis. Kernig's flexion contracture is practically always present. Rigidity of the neck is due to affection of the cerebellar fossae in otogenic meningitis. 
It is absent, if the process is localized exclusively in the cerebrum.

The rarieties of extension explain the numerous and changeable clinical symptoms. These may be partly of irritation; partiy of paralysis. They may be focal and they may be toxic. If focal, contralateral hemiplegias, motor and amnesic aphasia, etc.,may arise. Examples of toxic gymptoms are neuritis of the facial nerve and of the acousticus, disturbances of respiration, and signs of spinal participation, such as, pains in the sacrum, and incontinence of the urine and feces.

The fever is usually very high, but shows no characteristic features. The pulse is usually accelerated, and violent headaches are usually present. Optic neuritis is practically always absent in the non-complicated cases. As a rule, the fully developed picture of meningitis is absolutely unmistakable for whoever has seen it once.

(27) In small children, and in somewhat larger ones, a simple acute non-perforated otitis media may cause severe cerebral symptoms, which are very reminiscent of meningitis. As soon as the pus is emptied, through spontaneous or surgical paracentesis, these symptoms, having been due to serous meningitis or a collateral toxic meningo-encephalitis, disappear. 
Otogenic meningitis must be diagnosed early and differentiated from other endocranial complications which may be present. It must also be traced to its otogenic etfology, to distinguish it from tuberculous, syphilitic, or metastatic meningitides, which mav appear in the course of other infectious diseases. The otogenic origin of mentingitis is secured by the presence of suppuration of the middle ear and by the nature of this suppuration. It is practically unmistakable in the presence of suppuration of a cholesteatoma, and mastoiditis, and of symptoms indicating that the regions adjacent to the middle ear, such as the labyrinth, are involved.

The fact is important that meningitis may 'occur in apparently harmless forms of otitis media. The otitis may have a protracted course without any signs of mastoiditis or labyrinthitis. It may even appear after the discharge from the ear has stopped and the tympanum and hearing have become practically normal. In these cases, histological examination reveals that the suppurative process in the lateral parts of the temporal bone has subsided, while it continued to spread in the depth and to the apex of the pyramid. (22) In all cases, it is most important to de- 
tect the first symptoms of threatening meningitis, rather than to diagnose meningitis after it has fully developed. This is possible by a close watch over the otic suppuration, a careful neurological control, Immediate recognition of abnormal labyrinthine function and repeated examinations of the cerebrospinal fluid.

All signs which might pass for prodromal symptoms must be correctly interpreted: transient increases of the temperature, sensitivity to presgure in the retromandibular region, etc. If these symptoms are missing, the appearance of headaches and high temperatures, especially after a complaint-free interval, psychic irritability, hypersensitivity to noises, etc., must arouse suspicion.

In apoplectiform meningitis, which so often sets in with symptom of hemiplegia, and in which the symptoms follow each other so rapidly that prodromal, and terminal stages merge ofttimes, there are certain indications of the oncoming danger. They are excruciating headaches with slight increases of temperature, pains in the back, sometimes radiating into the legs, etc.

(15) An important means of recognizing meningits, and also of evaluating it course, is repeated chemical, cytological and bacteriological examination of the cerebro- 
spinal fluid obtained by lumbar puncture. It is also an aid in the differentiation of certain forms of meningitis as well as in the differential diagnosis with regard to other endocranial complications.

A cerebrospinal fluid containing 4 cells per cubic millimeter may be regarded as normal. If the fluid is undertension, but clear and stersle, and the cell elements on examination are not found to be increased, the meningitis is still at the serous stage. On the other hand, if the fluid is under pressure and is turbid from the presence of leucocytes, a purulent meningitis may usually by diagnosed.

(28) In the recumbent position, the pressure of the cerebrospinal fluid normally is 10 to 15 centimeters of water. In the sitting position, it is from 20 to 25.

(15) If organismare present in addition to pus-cells, a positive diagnosis of purulent meningitis may be made. Too much stress should not be laid, however, on the changes found in cerebrospinal fluid obtained by lumbar puncture. The fiuld may be clear and sterile, even in purulent meningitis, especially if localized in the middle cerebral fossa. The fluid may be turbid turbid though sterile, when a brain abscess is present. Normal cerebrospinal fluid contains $0.5 \%$ of globulin. 
In meningitis this is increased. The normal limits of glucose vary from $0.045 \%$ to $0.085 \%$. If sugar be diminished or absent, there is a microbic invasion of the cerebrospinal fluid. From $0.72 \%$ to $0.75 \%$ of chlorides is regarded as normal. If the chlorides fall below this the prognosis is very grave.

(27) The therapy of otogenic meningitis is surgical, as is that of all other endocranial complications of otitic origin. The causative purulent foci in the temporal bone must above all be radically evacuated. The the middle and posterior cranial fossae should be extensively exposed when indicated. If an affection of the labyrinth is present, the latter should be appropriately extirpated, with simultaneous opening of the fundus in the internal auditory meatus, which is usually the point of origin. Opening the fundus secures a sure drainage of the subarachnoid space. In the presence of a cerebral abscess, or in the presence of a sinus thrombosis, these complications must also be assailed operatively.

(25) Other measures procuring drainage and relief of pressure are: urotropine, internally and intravenously, 8 gn. In a $40 \%$ solution, in one dose; vuzin, intralumbarly; and autovaccines, especially intravenougly, under simultaneous administration of morphine which is said to stim- 
ulate the passage of the vaccine into the cerebrospinal fluid. When medicamentous treatment is adminsitered by the intralumbar route, it is essential to drain first a certain amount of spinal fluid, which also relieves pressure.

(29) Iumbar puncture is valuable because it eliminates many symptoms caused by intracranial pressure, and because it stimulates regeneration of a bactericidal cerebrospinal fluid. It can be performed safely every second day, and for some time, even every day.

Under certain circumstances, a suboccipital puncture may be commended. The cerebrospinal fluid obtained by suboccipital puncture affords a better insight into slight changes, and is less dangerous in the presence of disorders of communication with the spinal marrow.

The successful cures vary greatly in number, depending on whether all oases showing changes in the cerebrospinal fluid which might be interpreted as meningitic symptoms, hare been counted; or only cases of diffuse suppurative meningitis with poritive bacterial findings.

Haymann reports $37 \%$ of cures if cases with positive cerebrospinal fluids. Stewart claims the mortality is $93 \%$. The prognosis in children under 5 and in adults over 
30 is especially bad. Mygind states that between the ages of 15 and 30 , half his cases recovered.

(15) Meningitis due to chronic suppurative otitis media is less favourable than that due to the acute form, Yehingitisnfollowing labyrinthitis is of specially bad omen unless promptly treated. Meningitis associated with sinus thrombosis, has a better prognosis than meningitis associated with brain abscess. 


\section{CORCIUSIONS}

I. Otitis media is not of itself a serious menace to Iife. It is the intracranial complications which accompany or follow it that seriously endanger life.

II. The incidence of intracranial complications in cases of suppurative otitis media is about $10 \%$. Some writers report a higher percentage.

III. The principle complications from a standpoint of fatal issue, are sinus thrombosis, brain abscess and meningitis.

IV. The treatment of these complications is surgical.

V. Operation should be performed at the first signs of intracranial involvement. It is better to operate too early, than too late.

VI. The alm of operation should be to remove the primary focus in the middle ear, eliminate the paths of propagation, evacuate the thrombus or abscess and relieve intracrantal pressure. 


\section{BIBLIOGRAPHY}

(1) Hippocrates: "The Genuine Works of Hippocrates", translated by Frances Adams. W. Wood \& Co. New York. 1886.

(2) Hunter, Richard H.: "A Short History of Anatoing." 3rd Ed., J. Bale, Sons \& Danielsson, ltd., London, 1925.

(3) McCaskey, C. H.: "History of Otology." Jour. of Indiana Med. Ass. 16-132--135, 1923.

(4) Mollison, W. M.: "History of the Mastoid Operation." Jour. of Laryngology \& Otology, 45:95-101, 1930.

(5) Baas, Joh. Hermann: "The History of Medicine." J. F. Vail \& Co. New York. 1889.

(6) Garrison, Fielding $H_{.}:$"An Introduction to the History of Medicine." 4 th Ed., W. B. Saunders \& Co., Hew York. 1929.

(7) Wilmer, W. H.: "Early Eye \& Ear Infirmaries in the United Stater." Am. Jour. Opthalmology, 13:478490. 1930 .

(8) Yerger, C. F.: "Intracranial Complications of Suppurative Ot1tis Media." IIl. Med. Jour., 46:200 1924. nnVol. 2 .

(9) Swift, G. W.: "The Differential Diagnosis Between Septic Meningitis, Brain Abscess, and Lateral Sinus Thrombosis Complicating Mastoiditis." Annals of Otology, Rhinology \& Laryngology, $36: 669$. Sept. 1927.

(10) Breitste1n, M. L.: "Unusual Forms of Fxtension of Purulent Otitis Media." Laryngoscope, $33: 820$. 1923. 
(1I) Gaston, Alain: "Otitic Meningitis." Rev. d'otoneuro-opht. 9:397. June, 1931.

(12) Pietrantoni, I.: "Routes of Propagation of Inflamatory Middle Ear Processes to the Apex of the Petrous Bone, The Cavernous Sinus, The Sixth Pair of Nerves and the Gasserian Ganglion: The Venous Route," Arch. itol. d1. otol., $38: 296$. 1927.

(13) Crane, C. G.: "Laryngoscope," 1916, XXIV.

(14) Kopetsky, S. I.: "Intracranial Complications of Suppurative Otitis Media." Jour. A. M. A. $83: 336$, Vol. 2. Aug. 2nd, 1924 .

(15) Turner, A. Iogan, : "Diseases of the Nose, Throat \& Ear." 3rd Ed., William Wood \& Co. New York. 1932.

(16) Dacasta, John Chalmers, : "Modern Surgery." I0th"Ed., TI. B. Saunders Company, Philadelphia \& London. 1933.

(17) Kopetsky, S. J.: "Acute \& Chronic Otitis Hedia \& Sinus Thrombosis." 8:334-346. Arch. Otolaryng. 1928.

(18) Swift, G. W.: "The Differential Dignosis Between Septic Meningitis. Brain Abscess \& Lateral Sinus" Thrombosis Complicating Mastoiditis." Ann. Otol., Rhin. \& Laryng. $36: 669$ (Sept.) 192?.

(19) Cec1l, Rugsel I.: "A Text-Book of Medicine." 3rd Ed.. W. B. Saunders Company. Philadelphia \& London. 2933.

(20) Potts, John B.: "Thrombosis of the Lateral Sinus." Jour. of the A. M. A. 98:379-382. Jan. 30th 1932.

(21) Beck, Joseph C.: "Applied Pathology in Diseases of the Nose. Throat \& Ear." C. V. Mosby Co.. st. Louis. 1923. 
(22) Ballenger, William Iincoln,: Diseases of the Nose, Throat \& Ear." Lea \& Fediger, Philadelphia \& New York. 1914.

(23) Russi, P.: "The Diagnosis of Brain Abscess of Otitis Origin." Riforma med. $43: 585,1927$.

(24) Iund, R.: "Diagnosis \& Differential Diagnosis of Otogenic Cerebral Abscess." Hospitalstid 70:695 July 28. 1927; 719 (Aug. 14) 1927; 743 (Aug. 1I) 1927: Acta oto-1arvng. 11:479. 1927.

(25) Haymann, Iudwig: "Endocranial Complications from Suppurations of the Middle Ear and the Accessory Sinuses of the Nose." Munchener medizinische Wochenschrift. 79:828-831, Kay 20, 1932 .

(26) Eagleton, Wells P.: "Suppurative Meningitis of otitic \& Nadal Origin." Arch. of Otolaryng. 15:885, June. 1932.

(27) Eagleton. Wells P.: "Otitic Meningitis." Jour. A. M. A. $87: 1544$, Nov. 6, 1926 .

(28) Wechsler. Israel S.:" "A Text-Book of Clinical Neurology." 2nd Ed., W. B. Saunders Company. Philedelphia \& London. 1932.

(29) Globus, J. H. Kassanin, J. I.: "Pneumococclc Meningitis." J.A.M.A., $90: 599$, Feb. 25, 1928. 